Ciência Florestal, Santa Maria, v. 21, n. 2, p. 381-392, abr.-jun., 2011

\title{
IMPACTOS DA QUEIMA SOBRE ATRIBUTOS QUÍMICOS, FÍSICOS E BIOLÓGICOS DO SOLO
}

\author{
IMPACTS OF BURNING ON CHEMICAL, PHYSICAL AND BIOLOGICAL \\ ATTRIBUTES OF SOIL
}

Marciel Redin ${ }^{1}$ Gabriel de Franceschi dos Santos ${ }^{2}$ Pablo Miguel ${ }^{3}$

Genuir Luís Denega $^{4} \quad$ Manoeli Lupatini $^{5} \quad$ Alexandre Doneda $^{6} \quad$ Eduardo Lorensi de Souza $^{7}$

\section{RESUMO}

O objetivo deste estudo foi verificar por meio de revisão de literatura, os possíveis impactos do uso do fogo nos atributos físicos, químicos e biológicos do solo. Em relação aos atributos físicos, o fogo pode causar diminuição do volume de macroporos, do tamanho de agregados, da taxa de infiltração de água no solo e, consequentemente, sua umidade, aumento da resistência à penetração de raízes e da densidade do solo. Além disso, o solo torna-se mais susceptível ao processo erosivo pela remoção de sua cobertura vegetal. Nos atributos químicos, muitos trabalhos têm sido desenvolvidos com foco nas propriedades químicas, relatando aumento nos teores de $\mathrm{N}, \mathrm{P}, \mathrm{K}, \mathrm{Ca}, \mathrm{Mg}$, entre outros nutrientes mineralizados após a passagem do fogo em consequência das cinzas possuírem alta concentração desses nutrientes. A queima também reduz o aporte de matéria orgânica bruta e, consequentemente, altera o ciclo do carbono, contribuindo para a emissão de gases de efeito estufa para a atmosfera. Nos atributos biológicos, a ação da chama do fogo diminui a disponibilidade de alimento (fonte de energia) para os micro-organismos, diminuindo sobretudo a população da mesofauna do solo. De maneira geral, tomando por base os trabalhos revisados, concluise que a queima tanto de pastagens ou campos naturais bem como de resíduos culturais e áreas florestais, deve ser evitada como prática rotineira, pois de maneira geral, degrada direta ou indiretamente o solo. Entretanto, dependendo da situação e do sistema de produção, a queima pode ser uma opção de manejo a ser considerada.

Palavras-chave: fogo; nutrientes; atributos do solo.

ABSTRACT

The aim of this study was to verify through literature review the possible impacts of the use of fire on

1. Engenheiro Agrônomo, Doutorando do Programa de Pós-Graduação em Ciência do Solo, Centro de Ciências Rurais, Universidade Federal de Santa Maria, Av. Roraima, 1000, CEP 97105-900, Santa Maria (RS). marcielredin@gmail.com

2. Engenheiro Agrônomo, Mestre em Ciência do Solo, Instituto Federal de Educação, Ciência e Tecnologia Farroupilha, RS-377 Km 27, Passo Novo, CEP 97555-000, Campus Alegrete (RS). Telefone: (55) 3421-9600 Alegrete (RS).gfagro@gmail.com

3. Engenheiro Agrônomo, Doutorando do Programa de Pós-Graduação em Ciência do Solo, Centro de Ciências Rurais, Universidade Federal de Santa Maria, Av. Roraima, 1000, CEP 97105-900, Santa Maria (RS). tchemiguel@yahoo.com.br

4. Engenheiro Agrônomo, Doutorando do Programa de Pós-Graduação em Ciência do Solo, Universidade Federal do Rio Grande do Sul, Av. Bento Gonçalves, 7712, CEP 91.540-000, Porto Alegre (RS). genuirluis@gmail.com

5. Engenheiro Agrônomo, Mestranda do Programa de Pós-Graduação em Ciência do Solo, Centro de Ciências Rurais, Universidade Federal de Santa Maria, Av. Roraima, 1000, CEP 97105-900, Santa Maria (RS). mlupatini@gmail.com

6. Engenheiro Agrônomo, Doutorando do Programa de Pós-Graduação em Ciência do Solo, Centro de Ciências Rurais, Universidade Federal de Santa Maria, Av. Roraima, 1000, CEP 97105-900, Santa Maria (RS). alexandredoneda@gmail.com

7. Engenheiro Agrônomo, Doutorando do Programa de Pós-Graduação em Ciência do Solo, Centro de Ciências Rurais, Universidade Federal de Santa Maria, Av. Roraima, 1000, CEP 97105-900, Santa Maria (RS). elorensi@yahoo.com.br

Recebido para publicação em 27/10/2009 e aceito em 09/06/2010 
physical, chemical and biological attributes of soil. In relation to physical attributes, the fire may cause a decrease in the volume of macropores, the size of aggregates, the rate of infiltration of water into the soil and consequently its humidity, and an increase in the resistance to penetration of roots and soil density. Moreover, the soil becomes more susceptible to erosive process due to the removal of its vegetation cover. As for the chemical attributes, many studies focusing on chemical properties have reported an increase in levels of $\mathrm{N}, \mathrm{P}, \mathrm{Ca}, \mathrm{Mg}$, among others mineralized nutrients after the passage of fire because the ashes have high concentrations of those nutrients. Burning also reduces the input of organic matter and therefore alters the carbon cycle, contributing to the emission of greenhouse gases into the atmosphere. In relation to biological attributes, the action of flame fire reduces the availability of food (energy supply) for microorganisms, mainly reducing the population of mesofauna soil. In general, from the works reviewed, it appears that both the burning of pastures and natural fields as well as crop residues and forest areas, should be avoided as a routine practice, because in general, it directly or indirectly degrades the soil. However, depending on the situation and the production system, burning may be an option the be considered.

Keywords: fire; nutrients; soil attributes.

\section{INTRODUÇÃO}

O fogo foi uma das primeiras fontes de energia a ser dominada pelo ser humano e um fenômeno natural que sempre existiu na superfície do planeta, sendo também um dos responsáveis pela predominância de vários ecossistemas terrestres (SOARES, 1995). Embora possa caracterizar a evolução da civilização humana, sendo comum seu uso em muitas regiões tropicais e subtropicais, seu uso indevido também pode ser extremamente danoso a determinados ecossistemas (CARDOSO et al., 2003).

As queimadas podem ser provocadas direta ou indiretamente pelo homem. No Brasil, o fogo é utilizado, de modo geral, diretamente para: (a) limpeza de áreas tanto agrícolas como florestais, (b) renovar pastagens, melhorando a oferta e qualidade dos alimentos; (c) abrir novas fronteiras agrícolas, (d) melhorar o manejo de pré-colheita da cultura da cana-de-açúcar e (e) controlar pragas e doenças em culturas (anuais e perenes), em manejo pós-colheita, entre outras.

Um aspecto interessante a destacar é a distinção entre os termos utilizados na literatura. A queima controlada é a utilização do fogo de forma prescrita (ARAÚJO et al., 2005) e conduzida dentro de limites pré-estabelecidos de intensidade, com objetivo de apenas manejar a vegetação. No caso dos incêndios, não há controle das chamas e estas se propagam livremente, conforme as condições climáticas, topográficas e de material combustível, geralmente liberando grandes quantidades de energia e alcançando altas temperaturas.

Os impactos do fogo sobre a sustentabilidade dos ecossistemas, e em especial, ao solo, pode ser dado em decorrência de alterações na sua estrutura e funcionalidade (NEARY, 1999). Aliado a isso, Batmanian (1983) salienta que os efeitos do fogo são diretamente relacionados com as condições ambientais e com o tipo de material combustível e que sua intensidade e duração são dependentes de tais características. Segundo Rodrigues (1999), a frequência dos eventos também é um fator que deve ser considerado quando são avaliados os impactos nos atributos do solo.

Apesar de ser um método de manejo condenado, pela sua ação esterilizante e degradante (SPERA et al., 2000), o fogo controlado também pode ser considerado um aliado. Segundo Rheinheimer et al. (2003), a queima de campos no sul do Brasil é uma ferramenta usual e muito comum no manejo tradicional das pastagens, fundamentando-se na queima do pasto acumulado no período da seca, proporcionando assim um rebrote vigoroso e supostamente aumento na qualidade da pastagem. Ainda, de acordo com Behling e Pillar (2007), a queima das pastagens para estimular o seu rebrote após o inverno pode ser usada para controle da invasão de plantas arbustivas indesejadas. Entretanto, quando realizada com frequência, a queima da vegetação pode conduzir, a médio e longo prazo, por exemplo, à deterioração das propriedades químicas do solo (DICK et al., 2008), reduzindo seu potencial produtivo (HERINGER et al., 2002).

Assim, seguindo esse contexto, e considerando os relatos de Spera et al. (2000) e demais autores quando salientam que a ação do fogo, provoca de forma direta e indireta, uma série de modificações de natureza física, química (sobretudo) e biológica no solo, o presente trabalho objetiva investigar por meio de revisão de literatura, 
estudos que demonstrem os principais impactos que a queima ocasiona nos atributos físicos, químicos e biológicos dos solos.

\section{DESENVOLVIMENTO}

A ação do fogo pode ocasionar uma série de modificações na natureza física, química e biológica dos solos. Segundo Meirelles (1990), o fogo provoca mudanças pontuais ou definitivas na temperatura superficial do solo, no teor de umidade e na disponibilidade de água e nutrientes para as plantas. Ainda, Rheinheimer et al. (2003) salientam que em solos sob pastagem, a queima é usualmente utilizada para eliminar o material vegetal morto, para aumentar a disponibilidade de nutrientes no solo imediatamente após a queima e, assim, favorecer o rebrote e supostamente aumentar a qualidade da pastagem. Algumas espécies florestais precisam de calor do fogo para o aumento do seu poder germinativo como é o caso da bracatinga (Mimosa scabrella), para que suas sementes sofram a quebra da dormência.

De acordo com Carter e Foster (2004), estudos prévios relatam que a queima, em particular, tem mostrado efeitos benéficos para os ecossistemas em razão da forma de combustão do material orgânico, resultando na mineralização de nutrientes para o solo que serão rapidamente absorvidos pelas plantas. No entanto, como consequências da queima podem ocorrer modificações na taxa de infiltração e evapotranspiração da água do solo, na porosidade e no aumento do grau de suscetibilidade dos solos à erosão hídrica e eólica (CASSOL et al., 2004). Além disso, o solo desprotegido oferece uma maior possibilidade de lixiviação e percolação de nutrientes.

Nesse mesmo sentido, além das alterações descritas acima, Santos et al. (1992), comentam que ocorrem alterações biológicas nos solos submetidos à queima. Tais alterações, segundo o autor, são decorrentes do aumento na disponibilidade dos nutrientes, da alteração do $\mathrm{pH}$, do aumento da fonte de carbono (C) e da oxidação da matéria orgânica do solo (MOS). Vale ressaltar que ocorrem alterações momentâneas ou temporárias (BARRETA et al., 2005; PANDOLFO et al., 2004) nos atributos biológicos do solo, mas que em pouco tempo se recompõem ao estado original, anterior à queima.

\section{Efeito do fogo nos atributos físicos do solo}

Uma exploração agrícola sustentável precisa promover a melhoria da qualidade dos solos ou pelo menos, permitir sua manutenção. Porém, a intensificação da exploração agrícola, aliada ao seu uso e manejo inadequados, tem provocado modificações indesejáveis nas suas propriedades físicas (STONE e SILVEIRA, 2001).

A temperatura e intensidade da queima, que dependem do clima da região e época do ano em que ocorrem, bem como a natureza química da vegetação queimada, alteram a composição química do produto formado (POTES et al., 2010). A temperatura no interior do solo não se eleva muito durante a queima tradicional, chegando a no máximo $70^{\circ} \mathrm{C}$ a $2 \mathrm{~cm}$ de profundidade, aos $4 \mathrm{~min}$. de queima, conforme medida feita por Rheinheimer et al. (2003), utilizando sonda elétrica. Queimas de menor intensidade (temperatura $<350^{\circ} \mathrm{C}$ ) produzem maior quantidade de material carbonizado, porém com menor grau de aromaticidade do que queimas mais intensas (KNICKER et al., 2006; KNICKER, 2007) refletindo em menor acúmulo de MOS se comparado a queimas com temperatura mais elevada (KNICKER et al., 2006). Vale ressaltar que o problema está na perda de água por evaporação e esta pode ser muito elevada (DE BANO et al., 1979; HERINGER et al., 2002), afetando a camada superficial do solo (até $2 \mathrm{~cm}$ ) podendo originar assim uma camada compacta que dificulta a entrada de água no perfil do solo.

As principais alterações que podem ocorrer nas propriedades físicas de um solo são evidenciadas pela diminuição do volume de macroporos, do tamanho de agregados e da sua taxa de infiltração de água. Assim, pode ocorrer um aumento da densidade do solo e, consequentemente, da resistência à penetração de raízes (ALBUQUERQUE et al., 1995; CAVENAGE et al., 1999; UTSET e CID, 2001).

Nesse sentido, Ceddia et al. (1999) estudando queima em lavoura de cana, verificaram que a degradação das propriedades do solo é evidenciada pela redução do diâmetro médio ponderado dos agregados estáveis e pelo aumento da densidade do solo na profundidade de $0-5 \mathrm{~cm}$. Assim, nessas condições, os autores concluíram que pode ocorrer uma diminuição da velocidade de infiltração instantânea da água no solo, semelhante ao que poderia ocorrer nos trabalhos de De Bano et al. (1979) e Heringer et al. (2002). Ainda, aumentos na concentração de macroagregados estáveis em água, pela supressão da queima do canavial, foram registrados por Souza et al. (2005). Além disso, 
outros estudos encontraram correlação positiva entre concentrações da MOS e estabilidade de macroagregados (CERRI et al., 1991; BLAIR, 2000; GRAHAM et al., 2002).

A queima além de alterar a umidade do solo, em função das mudanças na taxa de infiltração e na taxa de transpiração, pode alterar, por consequência o estoque de água no solo. Sharrow e Wright (1977) constataram redução na infiltração e no armazenamento da água em um solo argiloso, nos Estados Unidos, sob pastagem nativa, quando submetida à queima com gasolina. No Brasil, resultados de estudos realizados em um Latossolo, mostraram que a queima promove a formação de uma crosta superficial e esta reduz a infiltração da água no solo (HERNANI et al., 1987). No entanto, essa baixa taxa de infiltração parece ser pontual, pois Meirelles (1990) não constatou diferenças significativas no teor de umidade entre áreas queimadas e não queimadas de uma gleba de campo sujo de Cerrado. Ao contrário de Hernani et al. (1987) e Meirelles (1990), Leite (1996) verificou, após um mês da queima, em Latossolo, aumento na taxa de infiltração de água no solo.

Mallik et al. (1984) observaram após a queima, em um Latossolo de clima temperado, um entupimento dos poros da camada superficial pelas cinzas. Tal efeito não foi observado por Hernani et al., (1987), em Latossolo sob clima tropical, embora Santos et al. (1992) tivessem verificado que a umidade do solo sob pastagem não queimada é o dobro da submetida à queima, e atribuíram essa diferença ao entupimento dos poros do solo pelas cinzas. No estado de São Paulo, Souza et al. (2004) avaliaram o efeito do fogo sobre a porosidade total, microporosidade e macroporosidade de um Latossolo cultivado com cana-de-açúcar. Segundo os autores ocorreu uma redução da porosidade total, microporosidade e macroporosidade pela ação do fogo, o que favoreu altas densidades de solo, sobretudo na camada de $0,2-0,4 \mathrm{~m}$ da superfície do solo.

$\mathrm{O}$ efeito de sistemas de colheita e manejo de cana crua (com e sem incorporação da palhada) e cana queimada sobre os atributos físicos do solo e produção de colmos foram comparados por Souza et al. (2005), em um Latossolo. No sistema de cana crua com incorporação da palhada, a maior produção de colmos foi alcançada, além de maiores valores de matéria orgânica, estabilidade de agregados, macroporosidade e teor de água no solo e menores valores de resistência do solo à penetração e densidade do solo, comparado ao sistema cana crua sem incorporação da palhada e cana queimada.

Em trabalho realizado por Spera et al. (2000) foram avaliadas as alterações das características físicas de um Latossolo submetido a seis anos de tratamento com fogo e sem fogo bianual. Não houve variações marcantes nas características físicas (densidade e retenção de água) do solo induzidas pelo fogo, exceto no aumento da umidade do solo nas parcelas não queimadas. Nas parcelas onde se aplicou o fogo, observou-se apenas uma tendência para o aumento da microporosidade, que pode ser atribuída à compactação promovida pelo impacto das gotas de chuva no solo desnudo. Entretanto, Meirelles (1990), não observou nas diferentes profundidades nenhuma diferença significativa entre as áreas queimadas e áreas não queimadas, quanto à umidade do solo.

A ação do fogo provoca uma série de modificações físicas do solo, e que, dependendo das condições do fogo, a queimada pode também refletir em muitas consequências negativas (GALANG et al., 2010). Por exemplo, o fogo expõe as superfícies minerais e pode aumentar a erosão do solo (CROMACK et al., 2000) e a manutenção da cobertura vegetal em sistema agroflorestal tradicional, sem o uso do fogo, controla a erosão e mantém os nutrientes no solo, melhorando a sustentabilidade do sistema (POMIANOSKI et al., 2006). Uma grande quantidade de material a ser queimado combinado com clima seco resulta em fogo intenso e cria as condições para expor as superfícies dos minerais. Isso foi demostrado através de fogos no sul da Geórgia e norte da Flórida nos Estados Unidos (GEORGIA FORESTRY COMMISSION, 2010).

\section{Efeito do fogo nos atributos químicos do solo}

De maneira geral, a queima da vegetação morta enriquece o solo da camada superficial na maioria dos nutrientes, por catalizar o processo da mineralização (RHEINHEIMER et al., 2003). Existem inúmeros trabalhos na literatura relatando aumentos nos teores de N, P, K, Ca e Mg mineralizados imediatamente após a passagem do fogo (CEDDIA et al., 1999; GATTO et al., 2003; RHEINHEIMER et al., 2003) em função das cinzas possuírem alta concentração de alguns desses nutrientes. Como as plantas somente absorvem nutrientes mineralizados, é natural que elas cresçam mais rapidamente em áreas queimadas. Entretanto, esses efeitos tendem a desaparecer, em médio prazo, 
na lixiviação dos nutrientes pela ação de chuvas, o que resulta em concentrações que podem ser até inferiores às observadas em solos que não sofreram ação do fogo (KNICKER, 2007).

Segundo Soares (1995) o empobrecimento do solo por meio do fogo pode ocorrer por incêndios de alta intensidade, que degradam quase toda a MOS e a maior parte dos nutrientes e por meio de queimas sucessivas que reduzem gradualmente o estoque de nutrientes do solo sem permitir a sua recomposição. Ainda, o mesmo autor afirma que esse fenômeno em uma comunidade florestal é potencializado pelas chamas.

Além disso, as queimadas aceleram a mineralização da MOS, liberam nutrientes, como N e P, para a solução do solo, deixando o N susceptível a perdas por percolação e volatilização (MROZ et al., 1980), eliminam a cobertura vegetal (BERTOL et al., 1997; HERINGER et al. 2002) e facilitam as perdas de solo e nutrientes por erosão hídrica (BERTOL et al., 1997) e eólica. Esse último aspecto, segundo Freitas e Sant'anna (2004) pode representar uma grande perda de elementos minerais pelo transporte das cinzas através de uma coluna de convecção de calor durante as queimadas. Ainda de acordo com o mesmo autor, esse processo pode representar perdas significativas em solos florestais já que o estoque de biomassa nesses ecossistemas geralmente são mais expressivos, o que propicia a ocorrência de fogo de alta intensidade, trazendo por consequências maiores perdas. Em relação a áreas de pastagens, é importante conscientizar os pecuaristas do grande desafio dos trabalhos nesta área (RHEINHEIMER et al., 2003), para, posteriormente, montar um modelo qualitativo e uma possível proposta de manejo sustentável das pastagens (FERNANDES, 1997).

Em relação ao efeito do fogo na MOS, os resultados obtidos são conflitantes e o impacto do fogo na quantidade e qualidade da MOS depende, especialmente, da intensidade do fogo, tipo de vegetação e textura do solo (KNICKER, 2007). Em solos sob floresta na região do Mediterrâneo, submetidos à ocorrência periódica de fogo espontâneo na estação seca, foi observado tanto aumento como diminuição do teor de $\mathrm{C}$ do solo (SANTÍN et al., 2008). Em contrapartida, estudo realizado com Latossolo sob cerrado submetido a 21 anos de queima, Roscoe et al. (2000) observaram redução drástica dos estoques de $\mathrm{C}$ e $\mathrm{N}$ na liteira, porém, nas amostras do solo, os teores de $\mathrm{C}$ e $\mathrm{N}$ não diferiram daqueles observados para duas áreas próximas, que não sofreram ação do fogo. Comportamento diferenciado foi constatado por Knicker et al. (2005), em Cambissolo de floresta de Pinus, da região mediterrânea da Espanha. Nesse solo, as queimadas espontâneas frequentes provocaram aumento de $100 \%$ nos teores de $\mathrm{C}$ e de $\mathrm{N}$ no horizonte $\mathrm{A}(0-15 \mathrm{~cm})$, quando comparado com uma área próxima que não foi queimada. No trabalho de Potes et al. (2010), o ambiente alterado periodicamente pelo fogo apresentou maior teor de matéria orgânica em camadas subsuperficiais e, em geral, maior proporção de estruturas quimicamente mais lábeis, comparativamente à pastagem sem queima.

Ceddia et al. (1999) trabalhando com dois sistemas de manejo de cana-de-açúcar, encontraram no tratamento com resíduo de cana crua, uma maior interação entre a fração orgânica e mineral do solo quando comparada ao tratamento com cana queimada. Esse material adicionado, quando em decomposição, origina uma série de compostos orgânicos, tais como açúcares, aminoácidos, ceras, fenóis, ligninas e ácidos (SHINITZER, 1991), que promovem a ligação entre as partículas orgânicas e minerais e/ou reduzem a molhabilidade da superfície do agregado (EMERSON et al., 1986).

Em geral, aumento na disponibilidade de P (SERRASOLSAS e KHANNA, 1995; GALANG et al., 2010) e no teor de bases trocáveis (RHEINHEIMER et al., 2003) são observados imediatamente após a queima, em consequência do acúmulo de cinzas na superfície do solo. Entretanto, esses efeitos tendem a desaparecer, em médio prazo, na lixiviação dos nutrientes pela ação de chuvas, o que resulta em concentrações que podem ser até inferiores às observadas em solos que não sofreram ação do fogo (KNICKER, 2007).

Galang et al. (2010) em condição de laboratório estudou as mudanças do $\mathrm{P}$ no solo de floresta de Pinus com 40 anos de idade em relação ao aquecimento $\left(100,200,300,500\right.$ e $\left.1000^{\circ} \mathrm{C}\right)$ do solo por um curto período de tempo $(2,5,5,15,30$ e 45 min.). Os resultados indicaram que na camada de $0-5 \mathrm{~cm}$ do solo, os estoques de $\mathrm{P}$ orgânico foram convertidos a $\mathrm{P}$ inorgânico e $\mathrm{P}$ total e essa conversão decaiu com o aumento da temperatura e do tempo. Além disso, a combinação de temperatura e tempo demostrou que o impacto sobre o P no solo é o mesmo utilizando, por exemplo, alta temperatura por pequeno período de tempo $\left(1000^{\circ} \mathrm{C}\right.$ por 2,5 min.) em comparação a mais baixa temperatura e tempo $\left(300^{\circ} \mathrm{C}\right.$ por $45 \mathrm{~min}$.). Em condição de campo 
no trabalho de Pomianoski et al. (2006), a queima dos resíduos da bracatinga (Mimosa scabrella Bentham) aumentou inicialmente a concentração dos nutrientes, sobretudo do $\mathrm{P}$, nas camadas de 1 a 2 cm do solo.

De Bano (1989) afirma que grandes quantidades de alguns nutrientes tais como $\mathrm{N}, \mathrm{S}$ e $\mathrm{P}$ podem ser volatizados durante um incêndio. Cátions, tais como $\mathrm{Ca}, \mathrm{Mg}, \mathrm{K}$ e $\mathrm{Na}$, não são volatizados, embora pequenas quantidades possam ser transferidas do sítio pela fumaça. Soares (1990) analisou os efeitos da queima controlada em povoamentos de Pinus caribaea e Pinus oocarpa. Os resultados indicaram que a concentração de $\mathrm{N}$ na serrapilheira foi reduzida em 44 e $39,2 \%$ e o $\mathrm{P}$ de 45 e $41,6 \%$ respectivamente. Os outros elementos analisados (K, $\mathrm{Ca}, \mathrm{Mg}, \mathrm{Fe}, \mathrm{Mn}, \mathrm{Cu}$ e B) aumentaram suas concentrações após a queima. Todos os elementos disponíveis (mineralizados) aumentaram significativamente, na camada superior do solo após o fogo, retornando aos níveis anteriores após 7 sete meses. Martin (1981) afirma que cerca de $60-80 \%$ do $\mathrm{N}$ existente no material combustível consumido pelo fogo é perdido para a atmosfera, mas geralmente aumenta a quantidade de $\mathrm{N}$ sob a forma disponível para as plantas. Schoch e Binkley (1986) relatam que as perdas de $\mathrm{N}$ nas queimadas de média e alta intensidade em povoamentos de diversas espécies de pinus varia de 50 a $200 \mathrm{~kg} \mathrm{ha}{ }^{-1}$. Recentemente, Oliveira et al. (2005) relatam que a ação do fogo com temperaturas acima de $400^{\circ} \mathrm{C}$ pode ocorrer perdas de $640,842,263,1520$ e $640 \mathrm{~kg} \mathrm{~N} \mathrm{ha-1}$; 4, 1,2, 11, 4 e 4 kg P ha-1; 42, 42, 12, 57 e $42 \mathrm{~kg} \mathrm{~K} \mathrm{ha}^{-1}$ nos ambientes de floresta, pastos com a forrageira Jaraguá, campo nativo, palhada de milho e cerrado, respectivamente.

Em trabalho realizado por Sampaio et al. (2003), o procedimento da queimada consumiu $36,3 \%$ da biomassa inicial e originou 5,5 $\mathrm{Mg} \mathrm{ha}^{-1} \mathrm{de}$ cinzas com significativas quantidades de nutrientes, sobretudo $\mathrm{Ca}, \mathrm{Mg}$ e $\mathrm{K}$. No balanço final, a área queimada sem cultivo apresentou maior perda de nutrientes do que a queimada e cultivada, denotando a importância da cobertura do solo na manutenção de elementos no sistema. Ao final do ciclo da cultura do arroz, ainda se verificou o efeito residual das cinzas no sistema, evidenciado pelos valores de $\mathrm{P}$, $\mathrm{K}, \mathrm{Ca}$ e $\mathrm{Mg}$ superiores aos do controle.

Em estudos realizados por Melo et al. (2006), em áreas de pastagens, cultivo de banana e de milho, mata queimada e não queimada o fogo não promoveu variações expressivas nos teores de Al trocável entre os ambientes, exceto no Latossolo cultivado com banana, cuja proximidade de afloramentos de rochas e evento de queima concorreram para o aumento dos teores de nutrientes na camada superficial. Nesse mesmo sentido, resultados experimentais obtidos por Gatto et al. (2003), evidenciaram que qualquer técnica de manejo do solo que venha acelerar o processo de mineralização, como a queima e o revolvimento do solo, contribui para a disponibilização mais rápida de nutrientes que poderão ser absorvidos pelas plantas ou, de alguma forma, perdidos do ecossistema.

Em relação a elementos que podem ser tóxicos às plantas, como por exemplo, o $\mathrm{Al}$, no trabalho de Coutinho (1990) foi observada uma diminuição do Al trocável nos solos do Cerrado após a queima, e isso pode ser atribuída à elevação do $\mathrm{pH}$ resultante do aumento da concentração de bases, conforme constatado por Ulery et al. (1993), em solos de floresta.

As propriedades químicas e biológicas estão interligadas e são afetadas pelo fogo de forma simultânea. Como exemplo, pode-se verificar a redução ou alteração da população microbiana, aumento temporário da disponibilidade de nutrientes, alteração no $\mathrm{pH}$, aumento da fonte de $\mathrm{C}$ e oxidação da MOS (SANTOS et al., 1992). No entanto, essas alterações possivelmente ocorram somente nos primeiros centímetros de solo. Segundo trabalho de Araújo et al. (1994), não foram observadas alterações nos teores de MOS e nos valores de CTC de um Latossolo sob pastagem nativa de Cerrado nas camadas abaixo de $3 \mathrm{~cm}$ de profundidade.

A perturbação antrópica de qualquer sistema estável (solo + cobertura vegetal) tende a causar mais perdas do que ganhos de $\mathrm{C}$, acarretando perda da qualidade do solo ao longo do tempo. Tais perdas são consequências da liberação de $\mathrm{CO}_{2}$ na respiração provenientes da decomposição da MOS por hidrólise microbiana, da lixiviação e perdas de compostos por erosão hídrica, sendo essas duas últimas vias de magnitude menor em solos subtropicais (BAYER, 1999).

Com relação às emissões de gases de efeito estufa, apesar da queima de resíduos na agricultura liberar uma grande quantidade de $\mathrm{CO}_{2}$ para a atmosfera, ela não é considerada líquida, pois, por meio da fotossíntese a mesma quantidade de $\mathrm{CO}_{2}$ é necessariamente absorvida durante o próximo ciclo de cultivo das plantas (MCT e EMBRAPA, 2002). Ainda, segundo o mesmo órgão de pesquisa, a principal cultura que envolve queima de resíduos

Ci. Fl., v. 21, n. 2, abr.-jun., 2011 
no Brasil é a cana-de-açúcar e em menor escala o algodão herbáceo e estima que, em 1994 as emissões provenientes da queima de resíduos, das duas culturas citadas acima, foram da ordem de $133 \mathrm{Gg}$ de metano $\left(\mathrm{CH}_{4}\right), 6,6 \mathrm{Gg}$ de óxido nitroso $\left(\mathrm{N}_{2} \mathrm{O}\right), 2787$ $\mathrm{Gg}$ de monóxido de carbono (CO) e $239 \mathrm{Gg}$ de $\mathrm{NO}_{\mathrm{x}}$ (outros óxidos de nitrogênio). Considerando que um $\mathrm{Gg}$ (giga grama) equivale a $1.000 \mathrm{Mg}$ e que apenas o $\mathrm{CH}_{4}$ e o $\mathrm{N}_{2} \mathrm{O}$ têm um potencial de aquecimento global (PAG) de 23 e 232 vezes superior ao $\mathrm{CO}_{2}$, respectivamente, esses resultados são extremamente preocupantes.

\section{Efeito do fogo nos atributos biológicos do solo}

A ação antrópica exercida no solo por meio das práticas agrícolas como queimadas, preparo convencional (aração e gradagens), plantio direto, entre outros, afeta em maior ou menor grau os micro-organismos e a fauna edáfica que utilizam o solo como habitat (LAVELLE et al., 1989) e, que por sua vez, exercem funções importantes no solo como a ciclagem de nutrientes (ASSAD, 1997). O solo está entre um dos mais complexos habitats do globo, sendo um sistema biológico pobremente conhecido (ASSAD, 1997; COLEMAN e GROSSLEY, 1995).

$\mathrm{O}$ fogo como forma de manejo das áreas de savanas e campos naturais, embora muito contestada no meio científico, por entidades ambientalistas e pela sociedade em geral, é uma realidade e prática comum em muitas regiões tropicais e subtropicais (CARDOSO et al., 2003). O efeito da queima sobre a vegetação e o solo pode variar de acordo com as condições ambientais no momento da passagem do fogo, com o tipo de solo da área, frequência da queima e quantidade de combustível disponível, que determina a intensidade e a duração da queima e que terá repercussão sobre a fauna do solo (BATMANIAN, 1983; RODRIGUES, 1999).

Ainda, o fogo age sobre o estrato arbóreo, influenciando sobretudo a redução do porte das árvores e o aumento da sua tortuosidade (RAMOS e ROSA, 1996) e da composição florística e estrutura da vegetação (LOPES et al., 2009). O estudo de Lopes et al. (2009) demostrou claramente que a área queimada apresentou menor número de indivíduos, de espécies, menor valor de área basal dos troncos das árvores de cerrado e, por conseguinte, do Índice de Diversidade de Shannon (H') e Equabilidade (J') e, portanto, o fogo exerceu papel relevante na modificação da estrutura da vegetação.

Os efeitos do fogo sobre a fauna do solo têm reflexos mais intensos nos níveis populacionais, sobretudo logo após a queima (ARAÚJO e RIBEIRO, 2005). Em estudo sobre a influência da severidade do fogo e do grau de desmatamento sobre a fauna do solo, Wikars e Schimmel (2001) constataram que logo após a queima ocorre redução no número de táxons. A maioria dos 17 táxons avaliados foi reduzida pelo fogo, exceto dois grupos de coleópteros (um na fase larval - Elateridae; e o outro na fase adulta - Cucujoidea). A população dos invertebrados pertencentes às ordens Collembola, Hemiptera e Hymenoptera foi reduzida a baixos níveis após o fogo, comparativamente àquela existente antes da queima.

A ação da chama diminui a quantidade de material orgânico que é a fonte inicial de energia dos micro-organismos que, assim, culmina na diminuição da população da mesofauna e, consequentemente, na perda da capacidade produtiva do solo (ASSAD, 1996). Assim, Barrat et al. (2006) estudaram o efeito que a queimada causaria na população de microartrópodos em uma pastagem nativa no sul da Nova Zelândia, com amostragens na primavera e no verão antes e após as queimadas. Os autores encontraram menores densidades populacionais de colêmbolos e ácaros nas parcelas que foram manejadas com fogo em relação as não queimadas. Esses resultados foram explicados pelos autores em razão do efeito imediato do fogo, que causa a morte dos organismos pelas altas temperaturas das chamas. Ainda, concluíram que houve um rápido reestabelecimento das populações após as queimadas e que não houve diferença entre épocas de amostragem. Boddey (1992) estudando o sistema de manejo de cana crua, deixando de queimar anualmente de 10 a $20 \mathrm{Mg} \mathrm{ha}^{-1}$, concluiu que esse sistema favorece a proteção de organismos controladores biológicos de pragas e doenças.

Malmström et al. (2009) estudaram o efeito da limpeza de área florestal com fogo na meso e macrofauna do solo após cinco anos da queima, e os resultados indicaram que, nas áreas queimadas, diminuiu a abundância de Collembola, Protura, Mesostigmata, Araneae e larvas de Diptera, e que Enchytraeidae, Lumbricidae, Oribatida, Prostigmata, Astigmata e Tardigrada diminuiram imeditamente após o fogo, mas que logo mostraram tendências à recuperação. Ainda segundo os mesmos autores, a riqueza de espécies também diminuiu no local queimado e a maioria delas ainda estavam ausentes após o período de recuperação.

Em trabalho conduzido por Baretta et al. (2005), que estudou o efeito do monocultivo de 
Pinus e da queima do campo nativo em atributos biológicos do solo no planalto sul catarinense, os maiores valores de liberação de $\mathrm{CO} 2$ foram encontrados em mata natural com predominância de Araucaria angustifolia e no reflorestamento de Pinus taeda com oito anos de idade, seguidos de campo nativo submetido à queima tradicional e campo nativo sem queima nos últimos 50 anos, respectivamente. Os maiores valores de $\mathrm{C}$ da biomassa microbiana (CBM), C orgânico total (COT) e relação CBM:COT foram encontrados na mata natural com predominância de Araucaria angustifolia, não tendo as demais áreas estudadas apresentado diferenças entre si. $\mathrm{O} q \mathrm{CO}_{2}$ foi maior no reflorestamento de Pinus taeda, seguido de campo nativo submetido à queima tradicional, em comparação com mata natural de araucária e campo nativo.

O uso continuado do solo pelo homem, com repetição de práticas agrícolas na mesma área, sobretudo por meio da agricultura, pode alterar o equilíbrio e a diversidade da fauna edáfica. Nesse sentido, Pandolfo et al. (2004) avaliaram diferentes sistemas de manejo do solo para um Nitossolo e um resultado interessante a destacar desse trabalho foi de que no tratamento com o uso associado de preparo convencional de solo (aração + gradagens) e queima da palhada ocorreu uma diminuição das populações de minhocas e formigas. As possíveis razões para esse resultado estão fundamentadas na diminuição da disponibilidade de alimento (matéria orgânica) ocasionada pela queima e posterior revolvimento do solo. Embora tenha havido um pequeno aumento da população de colêmbolos, esse não foi aparentemente significativo.

O fogo, além da meso e macrofauna também apresenta efeitos sobre os micro-organismos do solo. Nesse contexto, Nardoto e Bustamante (2003) estudaram o efeito do fogo sobre as taxas de mineralização líquida de $\mathrm{N}$ e biomassa microbiana do solo em áreas de cerrado. Os resultados indicaram um rápido aumento na biomassa microbiana no solo logo após a queimada da área e também um ligeiro decréscimo após exaurir as fontes de energia aos micro-organismos. Ambas as áreas apresentaram um mesmo padrão de mineralização/imobilização, mas com menor produção anual de $\mathrm{N}$ mineral na área queimada $\left(14,7 \mathrm{~kg} \mathrm{ha}^{-1}\right.$ por ano na área sem queima e $3,8 \mathrm{~kg} \mathrm{ha}^{-1}$ por ano na área queimada), um ano após a queima.

Pomianoski et al. (2006) estudaram o efeito do fogo nas características biológicas do solo no sistema agroflorestal tradicional da bracatinga (Mimosa scabrella Bentham) no município de Colombo, na parte norte da região metropolitana de Curitiba no período entre maio de 2002 e agosto de 2003. Concluiram em seu estudo que a queima dos resíduos da bracatinga influencia a quantidade de $\mathrm{C}$ da biomassa microbiana especialmente nas camadas de 1 a $2 \mathrm{~cm}$ do solo. Neary et al. (1999) enfatizaram que os efeitos sobre os micro-organismos são maiores em horizontes orgânicos e camadas superficiais de solo, em virtude das populações de micro-organismos serem mais abundantes nessas camadas.

Em trabalho de revisão de literatura, Araújo e Ribeiro (2005), abordaram estudos sobre os impactos do fogo sobre a microbiota (fungos e bactérias) e a fauna do solo em ecossistemas florestais. Após a análise desses estudos evidenciamse, sobretudo, os efeitos diretos do fogo e sua atuação sobre a diversidade e os níveis populacionais existentes, antes e após a queima, seja a queima de forma controlada ou não. De modo geral, a biota do solo afetada pela queima restringe-se aos primeiros centímetros do solo, devendo ser ressaltado que a intensidade dos danos está relacionada às variáveis ambientais (temperatura, umidade, relevo, solo e vegetação), bem como à intensidade e frequência do fogo, que são difíceis de ser controladas.

\section{CONCLUSÕES}

A ação do fogo provoca no solo, de forma direta ou indireta, uma série de modificações de natureza física, química e biológica. Essas modificações podem ser pontuais ou permanentes.

O grau de alteração depende de vários fatores, dentre os quais: tipo de solo, cobertura vegetal, duração, intensidade e frequência de uso.

No geral e a longo prazo, os benefícios do uso dessa prática são bem menores se comparados aos prejuízos gerados, decorrentes de sua utilização. É interessante que se busque opções que minimizem o uso da queima, e que a queima só seja utilizada em casos excepcionais.

\section{REFERÊNCIAS BIBLIOGRÁFICAS}

ALBUQUERQUE, J. A. et al. Rotação de culturas e sistemas de manejo do solo: efeito sobre a forma da estrutura do solo ao final de sete anos. Revista Brasileira de Ciência do Solo, Viçosa, v. 19, n. 1, p. 115-119, jan./abr. 1995.

Ci. Fl., v. 21, n. 2, abr.-jun., 2011 
ARAÚJO, Q. R. et al. Ação da queima e da percolação sobre propriedades químicas de um Latossolo Vermelho-amarelo, variação Una. Revista Ceres, Viçosa, v. 41, n. 237, p. 537-558, set./out. 1994.

ARAÚJO, E. A.; RIBEIRO, G. A. Impactos do fogo sobre a entomofauna do solo em ecossistemas florestais. Natureza \& Desenvolvimento, v. 1, n. 1, p. 75-85, jan./fev. 2005.

ASSAD, M. L .R. C. L. Recursos biológicos: ocorrência e viabilidade. In: SIMPÓSIO SOBRE O CERRADO; INTERNATIONAL SYMPOSIUM ON TROPICAL SAVANNAS, 1996, Brasília. Anais ... Planaltina: Embrapa-CPAC, 1996. p. 20-24.

ASSAD, M. L. L. Fauna do Solo. In; VARGAS, M. A .T.; HUNGRIA, M. (Ed.). Biologia dos solos dos cerrados. Planaltina: EMBRAPA-CPAC, 1997. p. 363-443.

BARETTA, D. et al. Efeito do monocultivo de pinus e da queima do campo nativo em atributos biológicos do solo no planalto sul catarinense. Revista Brasileira Ciência do Solo, Viçosa, v. 29, n. 29, p. 715-724, set./out, 2005.

BARRAT, B. I. P. et al. Effect of fire on microarthropods in New Zealand indigenous grassland. Rangeland Ecology \& Management, Durban, v. 59, n. 4, p. 383-391, july, 2006.

BATMANIAN, G. J. Efeitos do fogo sobre a produção primária e a acumulação de nutrientes do estrato rasteiro de um cerrado. 1983. $78 \mathrm{f}$. Dissertação (Mestrado em Ecologia)-Universidade de Brasília, Brasília, 1983.

BAYER, C. Dinâmica da matéria orgânica do solo. In: SANTOS, G. A.; CAMARGO, F. A. O. Fundamentos da matéria orgânica do solo - ecossistemas tropicais e subtropicais. Porto Alegre: Gênesis, 1999. p. 9-26.

BEHLING, H.; PILLAR, V. P. Late quaternary vegetation, biodiversity and fire dynamics on the southern Brazil highland and their implication for conservation and management of modern araucaria forest and grassland ecosystems. Philosophical Transactions B, v. 362, n. 1478, p. 243-251, feb. 2007.

BERTOL, I.; COGO, N. P.; LEVIEN, R. Erosão hídrica em diferentes preparos do solo após as colheitas de milho e trigo, na presença e ausência dos resíduos culturais. Revista Brasileira Ciência do Solo, Viçosa, v. 21, n. 3, p. 409-418, jul./set. 1997.

BLAIR, N. Impact of cultivation and sugar-cane green trash management on carbon fractions and aggregate stability for a Chromic Luvisol in Queensland, Australia. Soil and Tillage Research, Amsterdan, v. 55, n. 1, p. 183-191, jan./feb. 2000.

BODDEY, R. M. A importância de não queimar a palha na cultura da cana-de-açúcar. EMBRAPA/ CNPBS. In: CURSO SOBRE A BIOLOGIA DO SOLO NA AGRICULTURA, 2., 1992. Seropédica, RJ. 1992.

CARDOSO, E. L. et al. Efeitos da queima na dinâmica da biomassa aérea de um campo nativo no Pantanal. Pesquisa Agropecuária Brasileira, Brasília, v. 38, n. 6, p. 747-752, jun. 2003.

CASSOL, E. A. et al. Erosividade das chuvas em Taquari, RS, determinada pelo índice EI30, no período de 1963 a 1999. In: REUNIÃO BRASILEIRA DE MANEJO E CONSERVAÇÃO DE SOLO E ÁGUA, 15., 2004, Santa Maria. Anais... Santa Maria: SBCS, 2004.

CARTER, M. C.; FOSTER, C. D. Prescribed burning and productivity in southern pine forests: a review. Forest Ecology Management, Madison, v. 191, n. 1-3, p. 93-109, apr. 2004.

CAVENAGE, A. et al. Alterações nas propriedades físicas de um Latossolo Vermelho-Escuro sob diferentes culturas. Revista Brasileira de Ciência do Solo, Viçosa, v. 23, n. 4, p. 997-1003, out./dez. 1999.

CEDDIA, M. B. et al. Sistemas de colheita da canade-açúcar e alterações nas propriedades físicas de um solo Podzólico Amarelo no Estado do Espírito Santo. Pesquisa Agropecuária Brasileira, Brasília, v. 34, n. 8, p. 1467-1473, ago. 1999.

CERRI, C. C.; FELLER, C.; CHAUVEL, A. Evolução das principais propriedades de um latossolo vermelho escuro após desmatamento e cultivo por doze e cinqüenta anos com cana-deaçúcar. Cahiers Orstom, Série Pédologie, v. 26, n. 1, p. 37-50, 1991.

COLEMAN, D. C.; GROSSLEY, D. A. Fundamentals of soil ecology. San Diego: Academic Press, 1995. 205 p.

COUTINHO, L. M. O Cerrado e a ecologia do fogo. Ciência Hoje, Brasília, v. 12, n. 68, p. 22-30, 1990. CROMACK Jr., K. et al. Assessing the impacts of severe fire on forest ecosystem recovery. Journal of Sustainable Forestry, Washington, v. 11, n. 1-2, p. 177-228, jan. 2000.

DE BANO, L. et al. Effects of burning on Chaparral soils: I - Soil Nitrogen. Soil Science Society America Journal, Madison, v. 43, n. 3, p. 504-509, 1979.

DE BANO, L. F. Effects of fire on chaparral soil 
in Arizona and California and postfire management implications. In: SYMPOSIUM ON FIRE AND WATERSHED MANAGEMENT. 1989, Sacramento. Procedings. U.S.D.A . Forest Service, Berkeley, PSW-109, 1989, p. 55-62.

DICK, D. P. et al. Impacto da queima nos atributos químicos do solo, na composição da matéria orgânica e na vegetação. Pesquisa Agropecuária Brasileira, Brasília, v. 43, n. 5, p. 633-640, maio 2008.

EMBRAPA - Empresa Brasileira de Pesquisa Agropecuaria. Emissões de gases de efeito estufa na queima de resíduos agrícolas. Primeiro inventário brasileiro de emissões antrópicas de gases de efeito estufa. Relatórios de Referência. 2002.

EMERSON, W. W.; FOSTER, R. C.; OADES, J. M. Organo-mineral complexes in relation to soil aggregation and structure. In: HUANG, P. M.; SCHNITZER, M. (Eds.). Interactions of soil minerals with natural organics and microbes. Madison: Soil ScienceSociety of America, 1986. p. 521-548. (Special Publication, n.17).

FERNANDES, V. B. B. A queima de campos nativos no planalto catarinense, em especial no Município de Lages: Subsídios para uma proposta de gerenciamento ecológico. 1997. 111 f. Dissertação (Mestrado)-Universidade Federal do Rio Grande do Sul, 1997.

FREITAS, C. L.; SANT'ANNA, G. L. Efeitos do fogo nos ecossistemas florestais. Revista da madeira, Curitiba, v. 13, n. 79, p. 106-112, mar. 2004.

GALANG, M. A; MARKEWITZ, D.; MORRIS, L. A. Soil phosphorus transformations under forest burning and laboratory heat treatments. Geoderma, Amsterdan, v. 155, n. 3-4, p. 401-408, mar. 2010. GATTO, A. et al. Efeito do método de preparo do solo, em área de reforma, nas suas características, na composição mineral e na produtividade de plantações de Eucaliptus grandis, Revista Árvore, Viçosa, v. 27, n. 5, p. 635-646, set./out. 2003.

GEORGIA FORESTRY COMMISSION. Disponível em: <(http://www.gfc.state.ga.us/2)> Acesso em: 02 de junho de 2010.

GRAHAM, M. H.; HAYNES, R. J.; MEYER, J. H. Changes in soil chemistry and aggregate stability induced by fertilizer applications, burning and trash retention on a long-term sugarcane experiment in South Africa. European Journal of Soil Science, Oxford, v. 53, n. 4, p.589-598, dec. 2002.

HERINGER, I. et al. Características de um Latossolo Vermelho sob pastagem natural sujeita à ação prolongada do fogo e de práticas alternativas de manejo. Ciência Rural, Santa Maria, v. 32, n. 2, p. 309-314, mar./abr. 2002.

HERNANI, L. C. et al. Influência de métodos de limpeza de terreno sob floresta secundária em Latossolo amarelo do Vale do Ribeira, SP. II. Perdas por erosão. Revista Brasileira de Ciência do Solo, Viçosa, v. 11, n. 2, p. 215-219, 1987.

KNICKER, H. et al. Wildfire induced alterations of the chemical composition of humic material in a Dystric Xerochrept under a Mediterranean pine forest (Pinus pinaster Aiton). Soil Biology and Biochemistry, Oxford, v. 37, n. 4, p. 701-718, apr. 2005.

KNICKER, H. et al. Characteristic alterations of quantity and quality of soil organic matter caused by forest fires in continental Mediterranean ecosystems: A solid-state 13C NMR study. European Journal of Soil Science, Oxford, v. 57, n. 4, p. 558-569, may 2006.

KNICKER, H. How does fire affect the nature and stability of soil organic nitrogen and carbon? A review. Biogeochemistry, Dordrecht, v. 85, n. 11, p. 91-118, mar. 2007.

LAVELLE, P.; PASHANASI, B. Soil macrofauna and land management in Peruvian Amazonia (Yurimaguas, Loreto). Pedobiologia, Jena, v. 33, n. 5, p. 283-291, 1989.

LEITE, L. L. Densidade global e infiltração de água no solo em área de Cerrado submetida à queima controlada no Distrito Federal, Brasil. In: MIRANDA, H. S. et al. Impactos de queimadas em áreas de Cerrado e Restinga. Brasília: UnB, 1996. p. 31-36.

LOPES, S. F; DO VALE, V. S.; SCHIAVINI, E. I. Efeito de queimadas sobre a estrutura e composição da comunidade vegetal lenhosa do cerrado sentido restrito em Caldas Novas, GO. Revista Árvore, Viçosa, v. 33, n. 4, p. 695-704, jul/ago. 2009.

MALLIK, A. V. et al. Ecological effects of heather burning. I. Water infiltration, moisture retention and porosity of surface soil. Journal of Ecology, Oxford, v. 72, n. 3, p. 767-776, 1984.

MALMSTRÖM, A. et al. Dynamics of soil meso and macrofauna during a 5-year period after clearcut burning in a boreal forest. Applied Soil Ecology, Amsterdam, v. 43, n. 1, p. 61-74, sep. 2009.

MARTIN, R. E. Precribed burning techniques to maintain or improve soil productivity. In: HOBS, S. D.; HELGERSON, O. T (Eds). Reforestation of skeletal soils: Proccedings of a workshop; 1981. November 17-19. Medford, OR. Corvallis, 
OR.: Forest Research laboratory, Oregon State University; 1981, p. 66-70.

MELO, V. F. et al. Caracterizacão física, química e mineralógica de solos da colônia agrícola do Apiaú (Roraima, Amazônia), sob diferentes usos e após queima. Revista Brasileira de Ciência do Solo, Viçosa, v. 30, n. 1, p. 1039-1050, jan./fev. 2006. MEIRELLES, M. L. Efeito do fogo sobre a umidade do solo em área de campo sujo de cerrado. Ciência e Cultura, São Paulo, v. 42, n. 7, p. 359-360, jul. 1990.

MROZ, G. et al. Effects of fire on nitrogen in forest floor horizons. Soil Science Society America Journal, Madison, v. 44, n. 2, p. 235-242, 1980. NARDOTO G. B.; BUSTAMANTE M. M. C. Effects of fire on soil nitrogen dynamics and microbial biomass in savannas of Central Brazil. Pesquisa Agropecuária Brasileira, Brasília, v. 38, n. 8, p. 955-962, aug. 2003.

NEARY, D. G. et al. Fire effects on belowground sustainability: a review and synthesis. Forest Ecology and Management, Amsterdan, v. 122, n. 1-2, p. 51-71, sept. 1999.

OLIVEIRA, I. P. et al. Queimadas e suas conseqüências na região centro oeste. Revista Eletrônica Faculdade Montes Belos, Goiás, v. 1, n. 2, p. 88 -103, nov. 2005.

PANDOLFO, C. M. et al. Fauna edáfica em sistemas de manejo do solo e fontes de nutrientes. In: REUNIÃO BRASILEIRA DE FERTILIDADE DO SOLO E NUTRIÇÃO DE PLANTAS, 26., 2004, Lages, SC. Anais... Lages: SBCS/SBM, 2004.

POMIANOSKI, D. J. W.; DEDECEK, R. A.; VILCAHUAMAN, L. J. M. Efeito do fogo nas características químicas e biológicas do solo no sistema agroflorestal da Bracatinga. Boletim de Pesquisa Florestal, Colombo, [s.v], n. 52, p. 93118 jan./jun. 2006.

POTES, M. L. et al. Matéria orgânica em neossolo de altitude: influência do manejo da pastagem na sua composição e teor. Revista Brasileira de Ciência do Solo, Viçosa, v. 34, n. , p. 23-32, jan./fev. 2010. RAMOS, A. E.; ROSA, C. M. M. Impacto das queimadas. In: DIAS, B. F. de S. (Coord.). Alternativas de desenvolvimento dos Cerrados: manejo e conservação dos recursos naturais renováveis. Brasília : Fundação Pró-Natureza, 1996. p. 34-38.

RHEINHEIMER, D. S. et al. Modificações nos atributos químicos de solo sob campo nativo submetido à queima. Ciência Rural, Santa Maria, v. 33, n. 1, p. 49-55, jan./fev. 2003.
RODRIGUES, C. A. G. Efeitos do fogo e da presença animal sobre a biomassa aérea e radicular, nutrientes do solo, composição florística, fenologia e dinâmica de um campo de capim-carona (Elyonurus muticus (Spreng.) 0. Ktze.) no Pantanal (sub-região da Nhecolândia). 1999. 285 f. Tese (Doutorado em Biologia Vegetal)Universidade Estadual de Campinas, Campinas, 1999.

ROSCOE, R. et al. Effects of fire on soil organic matter in a cerrado "sensustricto" from Southeast Brazil as revealed by changes in $\delta^{13} \mathrm{C}$. Geoderma, Amsterdan, v. 95, n. 1-2, p. 141-160, mar. 2000.

SAMPAIO, F. A. R. et al. Balanço de nutrientes e da fitomassa em um Argissolo Amarelo sob floresta tropical amazônica após a queima e cultivo com arroz. Revista Brasileira Ciência do Solo, Viçosa, v. 27, n. 6, p. 1161-1170, dez. 2003.

SANTÍN, C. et al. Wildfires influence on soil organic matter in an Atlantic mountainous region (NW of Spain). Catena, Amsterdam, v. 74, n. 3, p. 286-295, aug. 2008.

SANTOS, D. et al. Queimadas e erosão do solo. Informe Agropecuário, Belo Horizonte, v. 16, n. 176, p. 62-68, 1992.

SCHOCH, P.; BINKLEY, D. Prescribed burning increased nitrogen avaliability in a mature lobloly pine stand. Forest Ecology and Management, Amsterdan, v. 14, n. 1, p. 13-22, jan. 1986.

SERRASOLSAS, I.; KHANNA, P. K. Changes in heated and autoclaved forest soils of S.E. Australia. II. Phosphorus and phosphatase activity. Biogeochemistry, Oxford, v. 29, n. 1, p. 25-41, apr. 1995.

SHARROW, S. H.; WRIGHT, H. A. Effects of fire, ash, and litter on soil nitrate, temperature, moisture, and tobosagrass production in the rolling plains. Journal of Range Management, Denver, v. 30, n. 4, p. 266-270, july 1977.

SHINITZER, M. Soil organic matter: the next 75 years. Soil Science, Madison, v. 151, n. 1, p. 41-58, 1991.

SOARES, R. V. Effects of pine plantation prescribed burning on soil chemical properties in the savanna region of Minas Gerais state, Brasil. In: INTERNATIONAL CONFERENÇE ON FOREST FIRE RESEARCH, 1990, Coimbra. Proceedings. Coimbra: Universidade de Coimbra, 1990, p. 06-09. SOARES, R. V. Queimas controladas: prós e contras. In: FÓRUM NACIONAL SOBRE INCÊNDIOS FLORESTAIS, 1; REUNIÃO CONJUNTA IPEF/FUPEF/SIF, 3., 1995, Piracicaba. Anais... 
Piracicaba: IPEF, 1995, p. 6-10.

SOUZA, Z. M. et al. Variabilidade espacial de atributos físicos de um Latossolo Vermelho sob cultivo de cana-de-açúcar. Revista Brasileira de Engenharia Agrícola e Ambiental, Campina Grande, v. 8, n. 1, p. 51-58, abr. 2004.

SOUZA, Z. M. Sistemas de colheita e manejo da palhada de cana-de-açúcar, Pesquisa Agropecuária Brasileira, Brasília, v. 40, n. 3, p. 271-278, mar. 2005.

SPERA, S. T. et al. Características físicas de um Latossolo Vermelho-escuro no cerrado de Planaltina, DF, submetido à ação do Fogo. Pesquisa Agropecuária Brasileira, Brasília, v. 35, n. 9, p. 1817-1824, set. 2000.

STONE, L. F.; SILVEIRA, P. M. Efeitos do sistema de preparo e da rotação de culturas na porosidade e densidade do solo. Revista Brasileira de Ciência do Solo, Viçosa, v. 25, n. 2, p. 395-401, mar./abr. 2001.

UTSET, A.; CID, G. Soil penetrometer resistance spatial variability in a ferralsol at several soil moisture conditions. Soil Tillage Research, Oxford, v. 61, n. 3-4, p. 193-202, sept. 2001.

ULERY, A. L.; GRAHAM, R. C.; AMRHEIN, C. Wood-ash composition and soil $\mathrm{pH}$ following intense burning. Soil Science, Madison, v. 156, n. 5 , p. 358-364, nov. 1993.

WIKARS, L.; SCHIMMEL, J. Immediate effects of fire-severity on soil invertebrates in cut and uncut pine forests. Forest Ecology and Management, Amsterdan, v. 141, n. 3, p. 189-200, feb. 2001.

Ci. Fl., v. 21, n. 2, abr.-jun., 2011 